\title{
Percurso: entrevistas de psicanálise
}

$\mathbb{P}$ ARA QUEM acredita que a psicanálise é um saber esgotado e em vias de extinção, o livro Psicanálise entrevista é um excelente antídoto. Após 120 anos de uma turbulenta e influente história na cultura ocidental, o campo psicanalítico está vivo e diversificado, superando antigas muralhas entre as diferentes escolas de pensamento em torno do seu fundador, S. Freud, e "fazendo a psicanálise trabalhar", noção recorrente entre os entrevistados.

Trata-se de uma coletânea com dezoito entrevistas realizadas ao logo de 25 anos pela revista Percurso, do Departamento de Psicanálise do Sedes Sapientiae, com consagrados psicanalistas, filósofos e historiadores (às vezes ambos). São personalidades que abrangem três gerações - das décadas de 1950 a 1970 -, e que influenciam até hoje as reflexões e condutas dos profissionais atuantes na área, estrangeiros e brasileiros. Sendo o primeiro de dois volumes (o segundo promete mais dezessete entrevistas), e a julgar pela riqueza e alcance dos depoimentos deste, o leitor certamente aguardará o próximo com todo interesse.

Indispensável ler antes o belo prefácio de Renato Mezan, editor responsável pela Percurso e renomado psicanalista paulista. Como historiador da psicanálise e já abarcando os dois volumes, Mezan organiza para o leitor iniciante no assunto (e para os que não são também) a multiplicidade de linhas teóricas, criações e rupturas dos Institutos de formação de analistas nos eixos francês, anglo-saxão e latino-americano, orientando o nosso olhar para a gama de questões que as quase quatrocentas páginas envolvem. Assim, conhecemos não só os principais fatos do movimento psicanalítico internacional e nacional, suas crises e "disputas ferozes", mas também o intercâmbio entre as heranças dos grandes mestres a partir de Freud, nesse diálogo fecundo dos seus discípulos, dissidentes e/ou divulgadores da obra matriz.

Melanie Klein, Winnicott, Bion, Abraham, Ferenczi, Michael Balint e Lacan aparecem como nomes de uma pioneira apropriação crítica da psicanálise, citados por tantos entrevistados (seja para alinhar-se a eles ou para questioná-los), mostrando a pertinência da lição de Winnicott: "só se pode ser original apoiado na tradição" (citado por Ivone Lins, uma de suas discípulas).

Entre os entrevistados deste volume, embora o ramo francês seja o mais numeroso, encontramos representantes das mais importantes derivações do pensamento psicanalítico, nos últimos sessenta anos, seja na Europa (os franceses J.B.-Pontalis, André Green, Jean Laplanche, Jean Oury, Claude Le Guen, Monique Schneider, Joyce McDougall - nascida na Nova Zelândia e radicada em Paris -, a iugoslava Radmila Zigouris, que atuou na Argentina e há quarenta anos clinica em Paris e Otto Kernberg, austríaco que se fixa em Nova York), na América Latina (o uruguaio Marcelo Viñar e os argentinos Emílio Rodrigué, que se instala na Bahia em 1985, e Silvia Alonso, acolhida pelo Sedes desde 1977, quando chegou a São Paulo) e no Brasil (Isaías Melsohn, Chaim Samuel Katz, Joel Birman, Jurandir Freire Costa, Ivone Lins e 
o único não analista Sergio Paulo Rouanet). Um painel dos mais abrangentes.

O livro é radicalmente dialógico, não só porque a essência da entrevista é a interlocução - e cabe ressaltar que Percurso nos brinda com entrevistas brilhantes, tanto nas perguntas quanto nas respostas -, mas também pela rede de menções e referências entre os próprios entrevistados, formando uma teia comunicativa intensa. Afinal, é disso que vive a psicanálise, um saber feito de experiência, pesquisa, troca e transmissão que caminha pelo confronto profícuo das diferentes abordagens.

O conjunto dessas vozes díspares, tantas vezes apaixonadas e contundentes, como verá o leitor, abarca um vasto leque temático: a formação do analista, as contribuições sociais da psicanálise, a constituição do sujeito psíquico, relações entre sexualidade/criatividade/ loucura, novas patologias e subjetividades contemporâneas, relações entre psicanálise e violência, a droga e o mal, o feminino e a psicanálise, entre tantas outras preocupações. Em meio a esse debate, destaco algumas intersecções entre os entrevistados, deixando ao leitor outras tantas escolhas possíveis.

A entrevista de abertura, com Jean-Bertrand Pontalis, filósofo e psicanalista da terceira geração, é um dos pontos altos do livro e aborda, com beleza poética, o psiquismo originário, focalizando o que se perde na passagem do balbucio do bebê ao ser falante. A noção de "melancolia da linguagem" mostra, nas palavras de Pontalis, que a "a linguagem é o luto da coisa em si e ao mesmo tempo leva embora esse luto" (p.42). A dimensão sensível do infans (o não falante) guarda o que não cabe na palavra, um "fluxo sonoro, talvez uma música, que se reduz, seja porque a gente não lembra mais, seja porque não são articuladas sílabas, frases” (p.43). Esse resíduo, ou "amor dos começos" (título de seu livro de 1986), é perdido com a aquisição da linguagem articulada, mas ganha espaço nas artes e na escuta do analista. Proust ou Beckett, diz Pontalis, aluno de Sartre e coautor do conhecido Vocabulário de psicanálise, "sempre tentaram pesquisar esse fluxo - sonoro, visual, sensitivo que corre o risco de se perder nas palavras" (p.43). (Aqui entre nós, o mesmo indizível parece ecoar igualmente nas obras de Clarice Lispector e Guimarães Rosa, entre outros).

Da análise com Lacan, a seu ver "um tanto decepcionante", Pontalis conta que decide romper com seu analista quando percebe "que ele arrastava consigo discípulos, devotos, numa espécie de mimetismo que me exasperava terrivelmente, nas vestimentas, na maneira de falar, nos tiques e linguagem. Logo ele que havia denunciado o eu imaginário!" (p.37). Mas alerta: "Será que todas as análises não são decepcionantes?" (p.33).

Sobre "essa experiência muito bizarra, muito estranha, um pouco louca que é a análise", Pontalis acredita que nos dias atuais está menos inventiva, mais conformista e acha importante "reencontrar a efervescência do pensamento freudiano". Critica, ainda, o estado de dependência dos analistas com suas associações: "eu não me defino por um pertencimento”, afirma (p.52).

Aliás, o combate aos dogmatismos e autoritarismos de certas instituições formadoras perpassa várias entrevistas. Claude Le Guen, por exemplo, ainda que admire os postulados teóricos de Lacan, combate o que considera "as prá- 


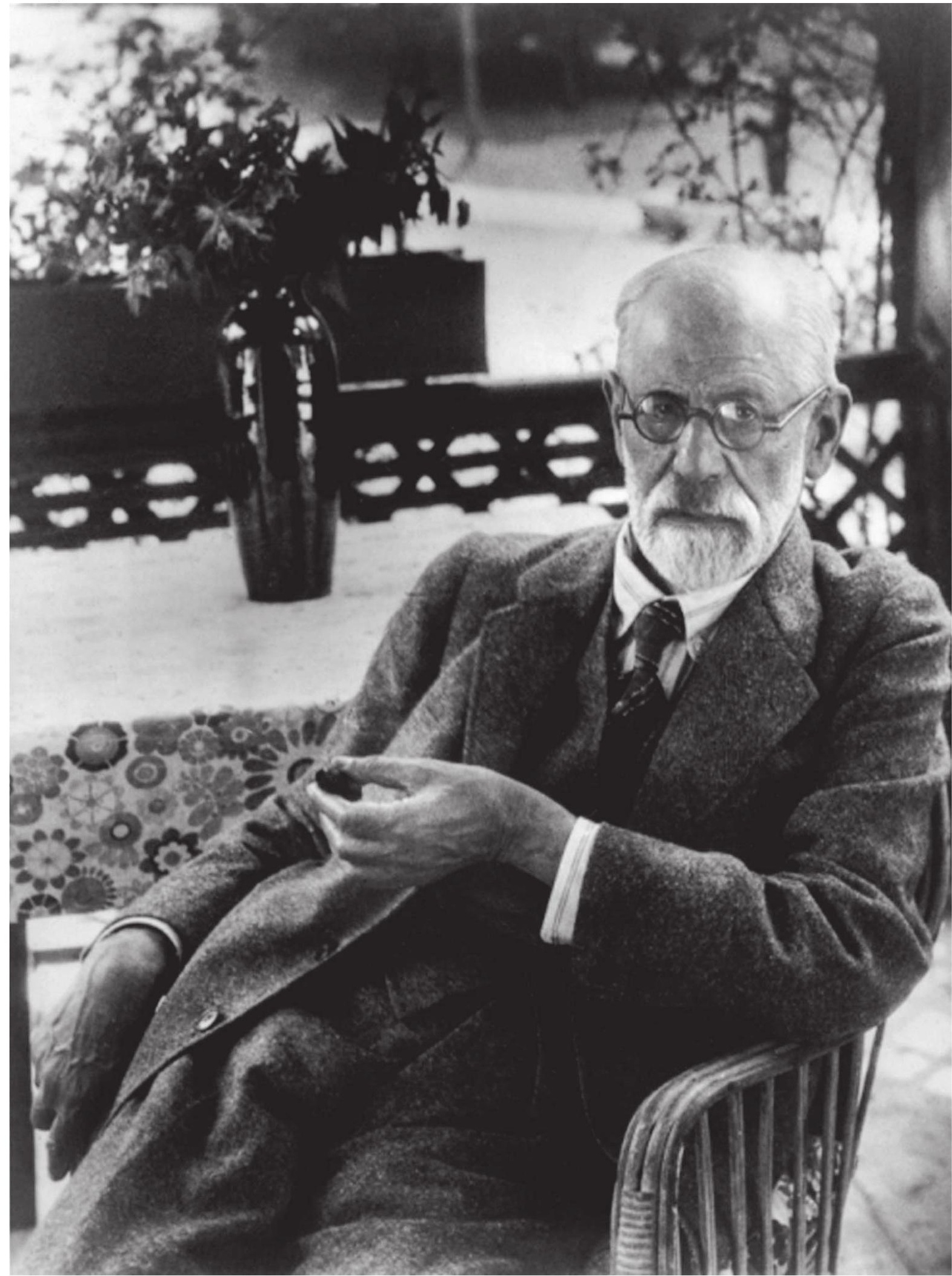

Sigmund Freud (1856-1939). 
ticas catastróficas" das sessões de tempo duráveis na clínica lacaniana (e a consequente "manutenção da dependência transferencial para além dos limites da cura"). Mas, ressalva que "não há nada mais estimulante do que ter alguém para combater". Como ele, Joyce McDougall também se opõe à “devoção incondicional a uma única escola [...], um obstáculo que impede seus partidários de escutar os seus pacientes e de procurar ir mais além quando esses últimos não se encaixam em seu enquadre teórico" (p.127).

Como contraste, leia-se a entrevista de Jean Oury, fundador da clínica La Borde em 1954, um dos pioneiros em psicoterapia institucional: "Estive em análise com Lacan uma vez por semana durante 27 anos, sou incurável! Eu frequentava todos os seus cursos e seminários, conheço tudo de cor e considero muito importante, a tal ponto que costumo dizer que Lacan é como o Guia Michelin” (p.87).

Mais forte, porém, é a desmistificação da aura do mestre francês, visível em muitas falas, sobretudo a de Radmila Zigouris, que teve Lacan como supervisor nos anos 1960, e que considera o manejo do tempo lógico "uma enganação calculada”. Para ela, Lacan "era sobrecarregado de tal maneira, que nem sempre podia escutar". A analisanda de Serge Leclaire vai mais longe no ataque: "a única pessoa que se matou durante meus longos anos de trabalho foi a paciente que eu supervisionava com Lacan” (p.189).

Não há dúvida de que um dos grandes nomes reverenciados ou exorcizados nessas entrevistas é o de Lacan, o que só reafirma o poder que exerceu em seus alunos, pacientes e supervisionandos diretos e indiretos.

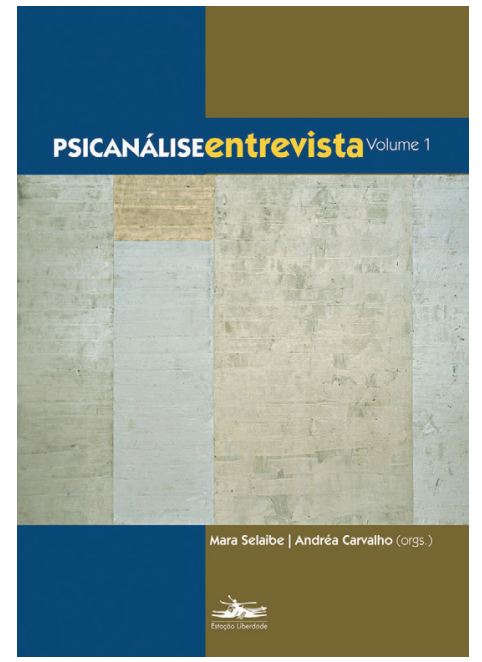

Psicanálise Entrevista - v.1.

Org. Mara Selaibe e Andrea Carvalho.

São Paulo: Estação Liberdade, 2014.

Outro eixo de problematização nas entrevistas são as relações entre psicanálise e sociedade, na busca de reconhecer as novas formações do inconsciente e suas sintomatologias contemporâneas no interior da complexa trama entre o sexual e o político. O tema surge em quase todas as conversas, sempre sob o viés de uma urgência. Para o psicanalista carioca Joel Birman, um dos principais teóricos do "mal-estar na modernidade", verifica-se uma mudança clara das histerias e neuroses clássicas centradas no modelo da conflitualidade para o que os franceses chamam de "estados-limite" marcados por "traços cada vez mais melancólicos”. Para Birman, “as questões do corpo e do narcisismo foram colocados cada vez mais em primeiro plano". Daí alguns autores mais antigos retornarem ao debate, como Ferenczi, Balint e Winnicott, adaptando-se aos paradigmas da moda por teorizarem estados narcísico-regressivos, ainda que Birman consi- 
dere seus modelos igualmente "jogos de linguagem" que não deveriam ser tomados como verdades absolutas. Quando aborda a medicalização crescente (Prozac ou outros tranquilizantes) e a adição, "duas faces da mesma moeda" em função da "exigência de performance e eficácia na ética da sociedade do espetáculo" (p.279), Birman é contundente: "elas vão numa direção evidentemente fálica, na qual busca-se eliminar a singularidade e o desamparo" (p.280).

A necessidade de um suporte de certezas não seria só do paciente que "busca a posição servil" a um mestre, seu analista. Também o Brasil, "com sua volúpia de colonizado", segundo Birman, buscaria nas grandes doutrinas psicanalíticas “cânones colonizadores, o que é uma tentativa de ter uma filiação paterna definida [...]" (p.285).

Posição semelhante aparece no notável depoimento de Marcelo Viñar, pensador do exílio, da tortura e da violência, para quem "as relações entre psicanálise e cultura local são cruciais" se a meta é evitar as importações teóricas alienantes. Sua proposta passa por uma "clínica da amostragem, observando como são nossos loucos, como são nossos meninos de rua", para então chegar a um universal enraizado na vida particular. Preocupado com "a descrição concreta de onde e como emerge a violência intolerável", Viñar critica categorias estáveis em que “o mal está substancializado". Apoiado em Hanna Arendt e Alain Badiou, afirma ser contra "pensar a violência como categoria independente das situações e acontecimentos" e propõe uma "semiologia prolixa" de narrativas teórico-clínicas para analisar "de onde emerge essa dose de crueldade e violência que é parte da vida humana" (p.232).
Já no campo das ligações entre psicanálise e estética, destaca-se a “aula” de Isaias Melsohn (1921-2009), referência na área quando se pensam os aspectos não discursivos da linguagem. Formado na filosofia de Ernst Cassirer e Susanne Langer, além de Husserl e Merlau-Ponty, Melsohn diferencia a expressividade mítica da vivência estética, ainda que perceba afinidades entre elas e suas ressonâncias na sessão de análise. Essa seria, para o psicanalista, "muito mais mítica do que estética - mítico como uma forma particular para designar uma situação de aprisionamento na emoção. Afinal, nós e os nossos pacientes somos humanos e não vivemos nas nuvens dos valores estéticos quando olhamos um outro" (p.169).

Igualmente densa é a entrevista com André Green, sobretudo quando discute a metapsicologia de Freud e mostra que "a pulsão é a matriz do sujeito". O registro da representação teria sido substituído, no segundo modelo tópico de Freud, pelas moções pulsionais (o Isso, agora interno ao aparelho psíquico), que são irrepresentáveis por excelência. Com isso, diz Green, é a própria cura que é posta em xeque, na medida em que essa se funda na linguagem. Ao final, a "interpretação fica encurralada".

Fechando o livro, o ensaísta e diplomata Sergio Paulo Rouanet não se mostra confiante nos avanços teóricos da psicanálise no terreno sociopolítico. E lança perguntas provocativas:

Em que medida várias patologias graves da nossa sociedade como, por exemplo, o imperialismo, o atual belicismo norte-americano, o renascimento dos fundamentalismos, a regularização das identidades étnicas, nacionais (com o que isso com- 
porta de perigoso) estão sendo objeto de uma análise teórica a partir de categorias psicanalíticas? Em que medida categorias como a pulsão de morte estão sendo usadas para explicar, por exemplo, os ataques suicidas dos palestinos? (p.360)

É preciso seguir o exemplo de Freud, segundo Rouanet, na articulação íntima entre as estruturas sociais de opressão e as distorções psíquicas. Indagado se a psicanálise ocuparia o lugar de uma utopia, Rouanet responde: "no plano individual, a utopia de um psiquismo transparente para si mesmo, e, no plano social, a utopia de uma sociedade regida pela razão. Duas coisas inatingíveis e irrenunciáveis" (p.364). Freud sabia que “a razão era um mero verniz na superfície do córtex", mas faz uma aposta no iluminismo, diz Rouanet, sabendo que pode perder. "É uma utopia realista."

Haveria muito mais a dizer deste livro, uma ótima iniciativa de suas organizadoras. Psicanálise entrevista é uma obra indispensável para quem quer conhecer os últimos sessenta anos da psicanálise e compreender por que ela continua sendo um saber perturbador no melhor dos sentidos.

Yudith Rosenbaum é professora de literatura brasileira na Universidade de São Paulo. @-yudith@uol.com.br

I Faculdade de Filosofia, Letras e Ciências Humanas, Universidade de São Paulo, São Paulo/SP, Brasil. 